\title{
Effect of Organic Production Systems on Quality and Postharvest Performance of Horticultural Produce
}

\author{
Francesco Giovanni Ceglie 1,2, Maria Luisa Amodio ${ }^{2}$ and Giancarlo Colelli ${ }^{2, *}$ \\ 1 Organic Agriculture Department, Mediterranean Agronomic Institute of Bari, CIHEAM-IAMB, Via Ceglie, 9, \\ Valenzano, BA 70010, Italy; ceglie@iamb.it \\ 2 Department of Science of Agriculture, Food and Environment, University of Foggia, Via Napoli 25, Foggia, \\ FG 71122, Italy; marialuisa.amodio@unifg.it \\ * Correspondence: giancarlo.colelli@unifg.it; Tel.: +39-320-439-4535
}

Academic Editor: Douglas D. Archbold

Received: 3 December 2015; Accepted: 14 March 2016; Published: 6 April 2016

\begin{abstract}
Organic standards include a well-defined set of practices and a list of technical tools that are permitted by regulation. Organic products are mainly purchased for their safety and absence of synthetic pesticide residues. Furthermore, a diet based on organic products claims to provide health benefits due to the high nutritional value compounds that are more concentrated in organic products compared to conventional ones. As the scientific basis of the differences between organically- and conventionally-grown fruits and vegetables is under debate, some of the published work, together with some recent unpublished results, will be covered in the present review. In addition, the effect of different approaches to organic horticultural production will be described. Many studies have confirmed lower nitrate content, especially in leafy vegetables, and higher antioxidant compounds in organically-grown fruits in comparison to conventional ones. A recent study reported organic kiwifruit as higher in ascorbic acid and total phenol content than conventional kiwifruit. These differences were maintained throughout cold storage. Similarly, in organic grapes, antioxidant-related compounds were significantly higher than in conventionally-grown grapes. Analogous results were obtained with organic strawberries grown in protected conditions. However, conventional products usually result in higher moisture content, and this should be taken into account to confirm the differences on a dry matter basis. Possible explanations for the effects of organic farming practices on nutritional quality and postharvest performance of fresh produce are the following: (i) organic amendments provide a high input of exogenous organic matter and of nutrients for a long period; in contrast, mineral fertilizers, allowed only in conventional farming systems, are highly concentrated in nutrients that are directly available for root uptake in a shorter time period; (ii) the use of synthetic pesticides (only possible in conventional agriculture) slows down defence mechanisms against pathogens, with the consequence of favoring primary metabolism; (iii) cultural practices may result in different plant composition and nutritional quality, which in turn influence cold storage performance of the products as these differences, both in fertility and pest management, affect the allocation of secondary plant metabolites (such as ascorbic acid and phenolic compounds).
\end{abstract}

Keywords: shelf life; secondary metabolites; oxidative stress; strawberry; tomato; nutrition

\section{Introduction}

Organic standards include a well-defined set of practices and a list of technical tools that are permitted by regulations (i.e., Reg n.889/08 in UE and the National Organic Program in U.S.). A diet based on organic products claims to provide health benefits due to the higher concentration of nutritional compounds compared to conventional ones, and the absence of pesticide residues [1]. The present challenge of feeding the world requires new strategies to ensure food security which is 
surely based on food availability and access, but also on food safety and nutritional quality. Organic production systems may be a way to ensure the sustainability of production, allowing preservation of natural resources for present and future generations, while providing a high quality and long shelf life of the product [2]. Despite the importance of this issue, few comparative studies have focused on postharvest aspects, and the scientific basis of the possible difference between organically- and conventionally-managed produce is still debated [3]. Some published studies, together with some recent unpublished results, will be covered in the present review. In particular, comparison studies that were conducted under similar environmental conditions with respect to climate, soil characteristics and availability of nutrients, have been considered for the effect of diverse pre-harvest practices on postharvest performance.

\section{Diverse Plant Response to Different Systems of Production}

The overall quality characteristics of the plant parts which are used as food are the result of the interactions among genotype, environmental conditions, cultural practices and postharvest handling and processing techniques. Any environmental factor that varies from the ideal potentially generates a stress which may either promote or inhibit specific plant responses. Such stress may lead to oxidative stress that produces reactive oxygen species (ROS) in the chloroplasts (free radicals like superoxide and molecular forms like singlet oxygen) and in the mitochondria (mainly superoxide). Ascorbic acid, glutathione, phenolic compounds, and alkaloids, among the antioxidants, are non-enzymatic defenses used by the plant to cope with this dangerous situation [4]. In general, an organic production system is a stressful system largely due to an insufficient supply of mineral nitrogen throughout the crop cycle, fostering phenolics and ROS which are natural defense substances. For organic plants, the content of secondary metabolites, that also include antioxidants, have been positively correlated with these natural defense substances [5]. However, antioxidant biosynthesis requires plant resource reallocation from primary metabolism to secondary metabolite production. As a consequence, cultural practices, both organic and conventional, may result in different plant composition and nutritional quality at harvest due to different biotic and/or abiotic stress conditions, which, in turn, influence the concentration of secondary metabolites.

\section{Quality and Postharvest Performances of Organic and Conventional Fruit and Vegetables}

In the scientific literature, different studies have claimed opposite results. Woëse et al. [6] and Smith Spangler et al. [3] estimated large but not statistically significant differences in quality between organic and conventionally-managed crops, which led them to conclude that the two production systems had similar qualitative characteristics. However, in the last decade, other studies have contributed to enlarge the dataset for this comparison. Lairon [7] confirmed the absence of pesticide residues in organic food ( $97 \%$ of samples had no detectable level of pesticide) and reported a lower content of nitrogen in organic vegetables in comparison to conventional ones. Similarly, Baranski et al. [8] concluded that the concentration of total nitrogen was $10 \%$ lower in organic compared to conventional crops (nitrate $30 \%$ and nitrite $87 \%$ lower) [9]. The low percentage of nitrogen forms was correlated with a high concentration of secondary metabolites (such as phenols and vitamins, which do not contain nitrogen). Several studies have confirmed elevated levels of secondary metabolites in organic carrots [10], sweet peppers [11], and tomatoes [12]. Other studies have reported opposite results with tomatoes [13] and carrots [14]. Plant secondary metabolites are important for their role in enhancing human health [15], and, as a result, much attention has been dedicated to this family of compounds in the recent comparison studies. Luthria [16] found similar phenolic acid content in eggplant cultivated with organic or conventional techniques. Chassy et al. [17] reported higher values of antioxidant activity in organic tomato and bell peppers, while D'Evoli et al. [18] found that total polyphenol content was higher in conventional plums, but ascorbic acid, $\alpha$-tocoferol, and $\beta$-carotene were higher in organic samples. Furthermore, the majority of studies comparing the polyphenol content of plant products from different farming systems indicated significantly higher 
concentrations of these substances in organic fruits and vegetables compared to conventional ones. Lairon [7] highlighted the high level of antioxidants, minerals, and dry matter in organically-grown products. However, conventional products usually result in higher water content, and this should be taken into account with the differences confirmed in terms of dry matter. Bourn and Prescott [19] observed higher dry matter content in organically-grown carrots and spinach in comparison with the conventional ones. Ceglie et al. [20] and Conti et al. [21] found a higher dry matter content in organic strawberries. Dry matter at harvest has been proposed as a promising predictor of post-harvest soluble solids in apples, also affecting the relative amount of mass that could be lost during cold storage [22]. Woëse et al. [6] reported no clear trend in the level of total sugar content in organic vegetables compared with conventional ones.

Different types and amounts of secondary metabolites at harvest may affect antioxidant changes during the cold storage period and determine the diverse postharvest performance of the products. Despite the relevance of the issue, few comparative studies have focused on such postharvest issues. Differences during cold storage in incidence of physiological disorders, soluble solids content, firmness, and mineral content have been reported [23,24]. After ethylene treatment, organic banana showed faster peel color changes, and lower gravimetric water balance and pulp/peel ratio, and impedance in comparison to conventionally-grown banana [25]. During simulated marketing conditions, organoleptic characteristics and resistance to deterioration were higher for organic strawberries in comparison to the conventional fruit [26]. Hasey et al. [27] reported higher soluble solids content and firmness in organically-grown kiwifruit compared with conventionally-grown kiwifruit. In contrast, Benge et al. [28] reported that conventional kiwifruit showed higher soluble solids content and similar softening behavior and decay than organic ones, analyzed at the same firmness stage. The levels of calcium in kiwifruit were negatively correlated with the incidence of soft patches. Moreover, higher levels of $\mathrm{Ca}$ as well as of $\mathrm{NO}_{3}{ }^{-}, \mathrm{Mg}, \mathrm{Fe}$, and $\mathrm{Zn}$ were observed at harvest and during 25 days of cold storage at $10{ }^{\circ} \mathrm{C}$ for conventional "Meyer" lemons (Citrus meyeri Tan.) in comparison with fruits from an organic orchard [29].

\section{Postharvest Performance of Organically and Conventionally Grown Kiwifruits}

Amodio et al. [30] compared postharvest performance of organic and conventional "Hayward" kiwifruit harvested at the same maturity stage. Fruit shape and peel characteristics before cold storage, maturity indices $\left(\mathrm{CO}_{2}\right.$ and $\mathrm{C}_{2} \mathrm{H}_{4}$ production, firmness, color, soluble solids content, and acidity) and compounds associated with flavor and nutritional quality (minerals, sugars and organic acids, ascorbic acid, total phenols, and antioxidant activity) were determined at $0,35,72,90$, and 120 days of cold storage at $0{ }^{\circ} \mathrm{C}$, and after 1 week of shelf-life simulation at $20^{\circ} \mathrm{C}$. At harvest, organic and conventional kiwifruit had similar soluble solids content. Conventional kiwifruit had a higher firmness and $\mathrm{L}^{*}$ value, and a lower hue angle and chromaticity, resulting in a lighter green color when compared with the organic kiwifruit. During cold storage, soluble solids content increased more in conventional than in organic kiwifruit. Concerning nutritional compounds, ascorbic acid, and total phenols were more concentrated in organic than conventional kiwifruit, resulting in a higher antioxidant activity. These differences were maintained throughout the cold storage period. The two production systems resulted in different morphological attributes since organic kiwifruits exhibited a larger total and columella area, smaller flesh area, more spherical shape, and thicker skin compared to conventional kiwifruit. Also, the levels of the main mineral constituents were higher in organic than in conventional kiwifruit.

\section{Postharvest Quality of Organic and Conventional White Table Grapes}

The effects of organic versus conventional production of table grapes grown at two locations were evaluated at harvest and during 14 days of cold storage at $0{ }^{\circ} \mathrm{C}$ (Amodio $e t$ al., unpublished). Respiration rate, firmness, color, soluble solids content, acidity, organic acids, ascorbic acid, total phenols, antioxidant activity, flavonols, and peel characteristics were determined at harvest and during cold storage. Only from one location, phenolic compounds were significantly higher in the organic 
table grapes ( $505.1 \pm 52.4 \mathrm{mg}$ gallic acid $/ 100 \mathrm{~g}$ ) than in the conventional ones ( $370 \pm 58 \mathrm{mg}$ gallic acid/100 g). Similarly, antioxidant activity was higher in organic grapes (1211 $\pm 134 \mathrm{mg}$ Trolox/100 g) than in conventional ones $(763 \pm 98 \mathrm{mg}$ Trolox/100 g). This difference was observed until the sixth day of cold storage. Vitamin $C$ in organic and conventional table grapes was similar at harvest and throughout cold storage. Storability was greatly affected by the agricultural system resulting in a shorter shelf-life for organic grapes, which scored the highest values for firmness and appearance.

\section{Organic vs. Conventional Products: Comparative Analysis in a "Cul De Sac"}

Organic and conventional production systems are comprised of a number of very diverse approaches: sequences of crop rotation, sources and quality of inputs, timing and doses of water and fertilizers, weed management and cover crop use, and pathogen and pest control. Organic and conventional farming cannot indeed be defined as two isolated clusters of agronomic practices. On one hand, it is possible to have high or moderate input intensity conventional farming systems. An example of the latter is the restricted use of chemical inputs by private standards (i.e., for commercial reasons), such as for "zero pesticide residues" labels. In contrast, organic farming relies on more complex agro-ecosystem management that includes leguminous crops and organic matter-based amendments, although it may also be managed with a simple input substitution based on the replacement of chemical fertilizers and pesticides with organic-allowed inputs. In the scientific literature, this process in known as "conventionalization" of the organic farming [31] which may be summarized as the development of organic farming practices that might not be sustainable but that are not excluded by organic regulations [32]. In particular, organic greenhouse production is a clear example of this. The highly intensive production levels recorded in greenhouse systems requires high availability of nutrients to sustain crop growth. As a consequence, organic growers simplify crop rotation, excluding cover crops, and use easily soluble organic fertilizers. These issues should be taken into account in studies that aim to compare the quality and post-harvest performances of organic vs. conventional farming systems. Comparative analyses have to face the heterogeneity of the circumstances; observed differences and/or similarities would not necessarily be related to certification systems of the products because organically-certified products might have been produced by a "conventionalized" organic system and vice-versa. If organic-conventional system comparisons implemented the same agronomic practices and only varied in the type of nutrient or pesticide input, this would not be an organic vs. conventional system comparison but a comparison of organic vs. conventional inputs [33]. In this respect, there is room to begin comparative analyses among different approaches to organic methods of production in order to appreciate, within the greater heterogeneous cluster of organic practices, the impact on the quality of an organic conventionalized system vs. other organic systems based on agro-ecological practices. Such comparison studies should be considered as investigations of the effects of pre-harvest practices on post-harvest quality and product shelf life. In this regard, two research studies are reported below as preliminary results of this promising research approach.

\section{Effects of Different Systems of Organic Production on Quality and Post-Harvest of Tomato}

Tomato, a climacteric fruit, represents a significant source of folate, vitamin C, polyphenols, and other antioxidants [34]. A conventionalized organic production system based on organic commercial fertilizers was compared with two organic production systems based on agro-ecological practices represented by (i) animal manure amendments and dead mulches of cover crops; or (ii) on-farm compost amended green manuring of cover crops. For the three production systems, tomato fruit respiration rate, morphological, physical, sensorial characteristics, and nutritional compound content were monitored. It was observed that dehydroascorbic acid was significantly higher in the conventionalized system for tomato fruit harvested at breaker and pink stages. However, this difference disappeared after 10 days of cold storage at $15^{\circ} \mathrm{C}$. Organic agro-ecological systems were able to obtain a similar tomato yield and fruit quality as the "conventionalized" organic system which used off-farm inputs only. This was confirmed both at harvest and during cold storage. Further 
information and results of this experiment have been reported [35]. It is worth noting that when the environmental conditions are similar in terms of climate, soil characteristics, availability of water, and soluble nutrients for the roots, any differences in the cultural practices (even relevant ones such as cover crop mixtures vs. bare soil, organic dead mulch vs. plastic mulch, manure vs. commercial organic fertilizers) did not affect crop quality and postharvest performance.

\section{Effects of Different Systems of Organic Production on Quality and Post-Harvest of Strawberry}

Ceglie et al. [20] compared quality characteristics and postharvest performance of organically- and conventionally-produced strawberry fruit. Three organic farming systems (two "agro-ecological" and one "conventionalized") were compared to a conventional system. The production system affected the quality parameters of the strawberries cultivated in unheated tunnels. Conventionally-grown strawberry fruit were greater in diameter, chroma values, and firmness compared to the organically-produced fruit regardless of the specific organic system. Vitamin C, malic acid, tartaric acid, fructose, and glucose content were higher in the organic strawberries compared to conventional fruit. In fact, organically-grown strawberries received the highest evaluation for sweetness and aroma. Similar results were obtained for different varieties in the same geographic area (South of Italy) as reported by Conti et al. [21]. During the entire period of cold storage titratable acidity, citric acid, and total phenol values presented a similar decreasing trend from all of the production systems. However, the two organic agro-ecological systems differed in some aspects from both the "conventionalized" organic and the conventional system of production. At harvest, ascorbic acid and sucrose concentration were higher in both the organic agro-ecological than in the other two systems. Furthermore, during the entire cold storage period, tartaric acid and total phenols were higher in fruit from the organic agro-ecological systems than in either the conventional or the "conventionalized" organic systems. Thus, a "conventionalized" organic system may be halfway between conventional farming and organic-agro-ecological systems both in terms of quality and in terms of environmental sustainability. In this regard, Reganold et al. [36] linked the high quality of organic strawberry fruit with the high capability and stress resilience of organically-managed soil. Further studies on other commodities and with a longer-term assessment perspective are necessary to individuate sets of cultural practices applicable under the organic regulation which may enhance the quality of organic produce.

\section{Conclusions}

This review represents a small contribution to the wider picture of the quality of horticulture produce resulting from systems of production. Organic production systems have the objective of including a rational use of natural resources with high quality and shelf life performance. In many cases, conventional farming systems have achieved such high results. Nowadays, organic agriculture is increasing in terms of area of production and number of operators. A wide set of solutions have been proposed which, although valid with respect to organic certification standards, still need scientific assessment concerning claims of sustainability and high quality production. More in-depth analyses may relate the organic vs. conventional comparison to the more general issue of pre-harvest effects on postharvest performance of crops. In this respect, the balance between primary and secondary metabolic pathways seem to be an important aspect resulting from the complex interaction of genotype, environment, and agricultural practices which lead to differences in quality and postharvest performance of fresh fruits and vegetables. The need to improve the quality of food available in the world in a sustainable way should orient research on agricultural practices to increase the nutritional composition of fresh fruits and vegetables and to enhance the shelf life.

Author Contributions: This work was a product of the combined effort of all of the authors. The authors equally contributed to the literature reviewing, to the manuscript writing and revisions.

Conflicts of Interest: The authors declare no conflict of interest. 


\section{References}

1. Oates, L.; Cohen, M.; Braun, L.; Schembri, A.; Taskova, R. Reduction in urinary organophosphate pesticide metabolites in adults after a week-long organic diet. Environ. Res. 2014, 132, 105-111. [CrossRef] [PubMed]

2. Rembiałkowska, E. Quality of plant products from organic agriculture. J. Sci. Food Agric. 2007, 87, $2757-2762$. [CrossRef]

3. Smith Spangler, C.; Brandeau, M.L.; Hunter, G.E.; Bavinger, J.C.; Pearson, M.; Eschbach, P.J.; Sundaram, V.; Liu, H.; Schirmer, P.; Stave, C.; et al. Are organic foods safer or healthier than conventional alternatives? A systematic review. Ann. Intern. Med. 2012, 157, 348-366. [CrossRef] [PubMed]

4. Gill, S.S.; Tuteja, N. Reactive oxygen species and antioxidant machinery in abiotic stress tolerance in crop plants. Plant Physiol. Bioch. 2010, 48, 909-930. [CrossRef] [PubMed]

5. Winter, C.K.; Davis, S.F. Organic foods. J. Food Sci. 2006, 71, R117-R124. [CrossRef]

6. Woëse, D.; Lange, C.; Boess, K.; Bogl, W. A comparison of organically and conventionally grown foods-Results of a review of the relevant literature. J. Sci. Food Agric. 1997, 74, 281-293. [CrossRef]

7. Lairon, D. Nutritional quality and safety of organic food. A review. Agron. Sustain. Dev. 2010, 30, 33-41. [CrossRef]

8. Barański, M.; Średnicka-Tober, D.; Volakakis, N.; Seal, C.; Sanderson, R.; Stewart, G.B.; Leifert, C. Higher antioxidant and lower cadmium concentrations and lower incidence of pesticide residues in organically grown crops: A systematic literature review and meta-analyses. Br. J. Nutr. 2014, 112, 794-811. [CrossRef] [PubMed]

9. Caruso, G.; Conti, S.; La Rocca, G. Influence of crop cycle and nitrogen fertilizer form on yield and nitrate content in different species of vegetables. Adv. Hortic. Sci. 2011, 25, 81-89.

10. Sikora, M.; Hallmann, E.; Rembiałkowska, E. The content of bioactive compounds in carrots from organic and conventional production in the context of health prevention. Rocz. Państw. Zakł. Hig. 2009, 60, 217-220. [PubMed]

11. Del Amor, F.M.; Serrano-Martinez, A.; Fortea, I.; Nunez-Delicado, E. Differential effect of organic cultivation on the levels of phenolics, peroxidase and capsidiol in sweet peppers. J. Sci. Food Agric. 2008, 88, 770-777. [CrossRef]

12. Pieper, J.R.; Barrett, D.M. Effects of organic and conventional production systems on quality and nutritional parameters of processing tomatoes. J. Sci. Food Agric. 2009, 89, 177-194. [CrossRef]

13. Rossi, F.; Godani, F.; Bertuzzi, T.; Trevisan, M.; Ferrari, F.; Gatti, S. Health-promoting substances and heavy metal content in tomatoes grown with different farming techniques. Eur. J. Nutr. 2008, 47, 266-272. [CrossRef] [PubMed]

14. Krejčová, A.; Návesník, J.; Jičínská, J.; Černohorský, T. An elemental analysis of conventionally, organically and self-grown carrots. Food Chem. 2016, 192, 242-249. [CrossRef] [PubMed]

15. Lundegårdh, B.; Mårtensson, A. Organically produced plant foods-Evidence of health benefits. Acta Agric. Scand. B 2003, 53, 3-15. [CrossRef]

16. Luthria, D.; Singh, A.P.; Wilson, T.; Vorsa, N.; Banuelos, G.S.; Vinyard, B.T. Influence of conventional and organic agricultural practices on the phenolic content in eggplant pulp: Plant-to-plant variation. Food Chem. 2010, 121, 406-411. [CrossRef]

17. Chassy, A.W.; Bui, L.; Renaud, E.N.C.; Van Horn, M.; Mitchell, A.E. Three-year comparison of the content of antioxidant micronutrients and several quality characteeristics in organic and conventionally managed tomatoes and bell peppers. J. Agric. Food Chem. 2006, 54, 8244-8252. [CrossRef] [PubMed]

18. D’Evoli, L.; Tarozzi, A.; Hrelia, P.; Lucarini, M.; Cocchiola, M.; Gabrielli, P.; Franco, F.; Morroni, F.; Catelli-Forti, G.; Lombardi Boccia, G. Influence of cultivation system on bioactive molecules synthesis in strawberries: Spin-off on antioxidant and antiproliferative activity. J. Food Sci. 2010, 75, 94-99. [CrossRef] [PubMed]

19. Bourn, D.; Prescott, J. A comparison of the nutritional value, sensory qualities, and food safety of organically and conventionally produced foods. Crit. Rev. Food Sci. Nutr. 2002, 42, 1-34. [CrossRef] [PubMed]

20. Ceglie, F.G.; Mimiola, G.; Dechiara, M.L.; Amodio, M.L.; Colelli, G. A comparative study of quality and post-harvest performances of organically and conventionally grown strawberry (Fragaria $\times$ ananassa DUCH. "Festival“"). In Proceedings of the 2nd Congress of the Italian Network for Research in Organic Farming-RIRAB, Rome, Italy, 11-13 June 2014. 
21. Conti, S.; Villari, G.; Faugno, S.; Melchionna, G.; Somma, S.; Caruso, G. Effects of organic vs. conventional farming system on yield and quality of strawberry grown as an annual or biennial crop in southern Italy. Sci. Hort. 2014, 180, 63-71. [CrossRef]

22. McGlone, V.A.; Jordan, R.B.; Seelye, R.; Clark, C.J. Dry-matter-A better predictor of the post-storage soluble solids in apples? Postharvest Biol. Technol. 2003, 28, 431-435. [CrossRef]

23. DeEll, R.; Prange, K. Postharvest physiological disorders, diseases and mineral concentrationsof organically and conventionally grown McIntosh and Cortland apples. Can. J. Plant Sci. 1993, 73, 223-230. [CrossRef]

24. Weibel, F.P.; Treutter, D.; Graf, U.; Haseli, A. Sensory and health related fruit quality of organic apples. A comparative field study over three years using conventional and holistic methods to assess fruit quality. In Proceedings of the 11th International Conference on Cultivation Technique and Ohytopatological Problems in Organic Fruit Growing, Weinsberg, Germany, 3-5 February 2004; pp. 185-195.

25. Nyanjage, M.O.; Wainwright, H.; Bishop, C.F.H.; Cullum, F.J. A comparative study on the ripening and mineral content of organically and conventionally grown Cavendish bananas. Biol. Agric. Hortic. 2001, 18, 221-234. [CrossRef]

26. Cayuela, A.; Vidueira, M.; Albi, A.; Gutierrez, F. Influence of the ecological cultivation of strawberries (Fragaria $\times$ ananassa cv. Chandler) on the quality of the fruit and on their capacity for conservation. J. Agric. Food Chem. 1997, 45, 1736. [CrossRef]

27. Hasey, J.K.; Johnson, R.S.; Meyer, R.D.; Klonsky, K. An organic versus conventional farming system in kiwifruit. Acta Hort. 1997, 444, 223-228. [CrossRef]

28. Benge, J.R.; Banks, N.H.; Tillmann, R.; Nihal de Silva, H. Pairwise comparison of the storage potential of kiwifruit from organic and conventional production system. N.Z. J. Crop Hort. Sci. 2000, 28, 147-152. [CrossRef]

29. Uckoo, R.M.; Jayaprakasha, G.K.; Patil, B.S. Phytochemical analysis of organic and conventionally cultivated Meyer lemons (Citrus meyeri Tan.) during refrigerated storage. J. Food Compos. Anal. 2015, 42, 63-70. [CrossRef]

30. Amodio, M.L.; Colelli, G.; Hasey, J.K.; Kader, A.A. A comparative study of composition and postharvest performance of organically and conventionally grown kiwifruits. J. Sci. Food Agric. 2007, 87, 1228-1236. [CrossRef]

31. Goldberger, J.R. Conventionalization, civic engagement, and the sustainability of organic agriculture. J. Rural Stud. 2011, 27, 288-296. [CrossRef]

32. De Wit, J.; Verhoog, H. Organic values and the conventionalization of organic agriculture. NJAS-Wagen. J. Life Sci. 2007, 54, 449-462. [CrossRef]

33. Seufert, V.; Ramankutty, N.; Foley, J.A. Comparing the yields of organic and conventional agriculture. Nature 2012, 485, 229-232. [CrossRef] [PubMed]

34. Charanjeet, K.; George, B.; Deepa, N.; Singh, B.; Kapoor, H. Antioxidant status of fresh and processed tomato. J. Food Sci. Technol. 2004, 41, 479-486.

35. Ceglie, F.G.; Muhadri, L.; Piazzolla, F.; Martinez-Hernandez, G.B.; Amodio, M.L.; Colelli, G. Quality and postharvest performance of organically grown tomato (Lycopersicon. Esculentum L. "Marmande") under unheated tunnel in Mediterranean climate. Acta Hort. 2015, 1079, 487-494. [CrossRef]

36. Reganold, J.P.; Andrews, P.K.; Reeve, J.R.; Carpenter-Boggs, L.; Schadt, C.W.; Alldredge, J.R.; Ross, C.F.; Davies, N.M.; Zhou, J. Fruit and soil quality of organic and conventional strawberry agro-ecosystems. PLOS ONE 2010, 5, e12346. [CrossRef]

(C) 2016 by the authors; licensee MDPI, Basel, Switzerland. This article is an open access article distributed under the terms and conditions of the Creative Commons by Attribution (CC-BY) license (http://creativecommons.org/licenses/by/4.0/). 